\title{
THE INFRABUCCAL POCKET OF A FORMICINE ANT: A SOCIAL FILTRATION DEVICE ${ }^{1}$
}

\author{
By T. Eisner ANd G. M. Happ \\ Department of Entomology, Cornell University
}

The importance of regurgitative feeding as a means for distributing liquid nutrient among workers, and from workers to larvae and queen, has long been recognized, and it is now generally agreed that this process is a most fundamental bond in the social life of many ants (Le Masne, 1953; Wallis, 1961; Wheeler, 1923; Wilson and Eisner, 1957). Unlike honeybees, which also feed one another by regurgitation, but which have their principal food reservoir outside their own bodies in the honeycomb, ants store liquids exclusively within the crops of the individual living workers. Crop storage and regurgitative feeding are probably most highly developed in the specialized and successful subfamilies Formicinae and Dolichoderinae. It is in these ants that the crop is most capacious (witness the fact that ants with "replete" castes are restricted to these subfamilies), and it is these that have a special device, in the form of an elaborately refined proventriculus, adapted to dam the posterior outlet of the distended crop (Eisner, 1957; Eisner and Brown, 1958).

In its basic features, the proventriculus of Dolichoderinae and Formicinae is really no different from that of other ants and of Hymenoptera in general. It is a mechanical pump, consisting of a strongly muscled bulb, with an anterior intake valve communicating with the crop, and a posterior outlet valve leading to the midgut. When nutrient is to be passed from foregut to midgut, the bulb is put into operation, and through a series of rhythmic compressions and decompressions, liquid is effectively pumped along. Whereas in most Hymenoptera the intake valve of the proventriculus is a more or less mobile portal, incapable of effective prolonged closure, and hence ill-adapted to withstand for protracted periods the liquid pressure from a filled crop, in formicine and most dolichoderine ants the portal valve is permanently restricted to a narrow cruciform cleft through which leakage of crop contents is virtually impossible. It is only during proventricular pumping that liquid is passed through the clefts under

\footnotetext{
${ }^{1}$ This study was supported in part by Grant E-2908 of the U. S. Public Health Service.

Manuscript received by the editor February 16, 1962.
} 
suction pressure from the activated bulb (Eisner, 1957; Eisner and Brown, 1958).

Aside from its obvious advantage in making prolonged crop storage possible, the permanent restriction of the proventricular portal poses a problem. Solid particles passed into the crop have no place to go, since they obviously cannot be pumped through the proventriculus. What, then, happens to indigestible solids that are swallowed? Or are they perhaps not swallowed at all? Ants, as well as many other Hymenoptera, have a so-called infrabuccal chamber, a ventral infolding of the hypopharyngeal surface, that could conceivably act as an effective solid-withholding device, guarding the opening to the crop. Janet ( $1895 \mathrm{a}, \mathrm{I} 895 \mathrm{~b}$, I905) has described the anatomy of this structure, and has shown that in both ants and wasps, debris gathered while cleaning themselves or their nestmates, as well as solid residue from food ingested, often collects in this pocket and is ejected intermittently as small discrete pellets. His observations were excellent, but left some basic questions unanswered. The present study deals with an experimental evaluation of the function of the infrabuccal pocket of a formicine ant, Camponotus pennsylvanicus (DeGeer), in which crop storage and regurgitative food transmission are known to be welldeveloped social attributes (Plate 6).

Several laboratory-maintained colonies of Camponotus were available, but only nestmates, rather than internidally mixed lots, were used for any one series of tests. For experimental purposes they were fed honey mixed with various samples of corundum powder ranging in particle diameter from $\mathrm{I} O \mu$ to $300 \mu$.

\section{EXPERIMENTS WITH INDIVIDUAL ANTS}

An initial series of tests was designed to determine just how effective a filtering device the infrabuccal pocket really is. Individual ants, including only medium-sized workers, were confined in Petri dishes in which they had access to single drops of honey-corundum mixture. Eight corundum samples were tested (IO, 20, 30, 80, IOO, I5O, 200, and $300 \mu$ ), each on IO-I 5 ants. The ants were starved for one or more days before the tests, and, when introduced into the dishes, each would promptly commence feeding and remain at the food source uninterruptedly for up to several minutes. Only in a few exceptional cases would an ant pause briefly partway through the meal and, after backing away slightly and spreading its mandibles, would regurgitate a small, typically kidney-shaped infrabuccal pellet, consisting of a densely clumped packet of corundum plus small pieces of wood and other 
residual matter that the infrabuccal pocket must have contained before the meal. As soon as the ants had gorged themselves and ceased feeding they were drowned and their crops and infrabuccal chambers examined under a microscope for corundum content. The crops were dissected out and mounted intact in clearing medium, while the infrabuccal pockets were induced to discharge their contents simply by pressing the sides of the heads, causing the pockets to be everted. An alternative technique was to examine crops and infrabuccal chambers in intact corpses, after rendering their body cuticle transparent by prolonged immersion in $10 \%$ aqueous $\mathrm{KOH}$. The results were clearcut. Ants fed on the $200 \mu$ and $300 \mu$ samples had no corundum particles in their infrabuccal pockets and none in their crops: particles of such caliber are evidently excluded altogether by the mouthparts themselves, and they never even reach the infrabuccal chamber. Particles of the next smaller size tested ( $150 \mu)$ did get taken in, but only as far as the infrabuccal pocket, which was invariably packed tightly with them; the crops were always clear. With the remaining samples ( $10-100 \mu$ ) the infrabuccal chambers were also replete with corundum, but a substantial amount of particles had also been swallowed into the crop (Plate 7). Evidently the narrow transverse slit by which food gains entrance to the pharynx just above the infrabuccal chamber is of such aperture as to bar particles larger than $150 \mu$ but not those of IOO $\mu$ or less.

An additional experiment supported these findings. A group of ten ants were fed individually on a honey sample as before, but this time the mixture had particles of three sizes ( Iо, IоO, and $300 \mu$ ). As expected, the crops contained primarily Iо $\mu$-particles, the infrabuccal chambers mainly I00 $\mu$-particles, and the $300 \mu$-particles were not recovered at all.

It is clear from the preceding that the filtering action of the infrabuccal chamber is far from perfect, at least for particles smaller than $150 \mu$. Since the capacity of the chamber is limited, and since the individual ant as a rule does not pause to rid itself of an infrabuccal pellet every time the chamber is filled, but continues feeding even after the chamber is full and no longer operative, one is led to believe that in the normal course of food gathering a considerable amount of particulate matter is likely to find its way into the crop of the individual foraging ant. The experiments described next below were designed to establish the fate of such particles, which must obviously be voided in some fashion, or the crop would become solid-bound and the proventriculus obstructed. 


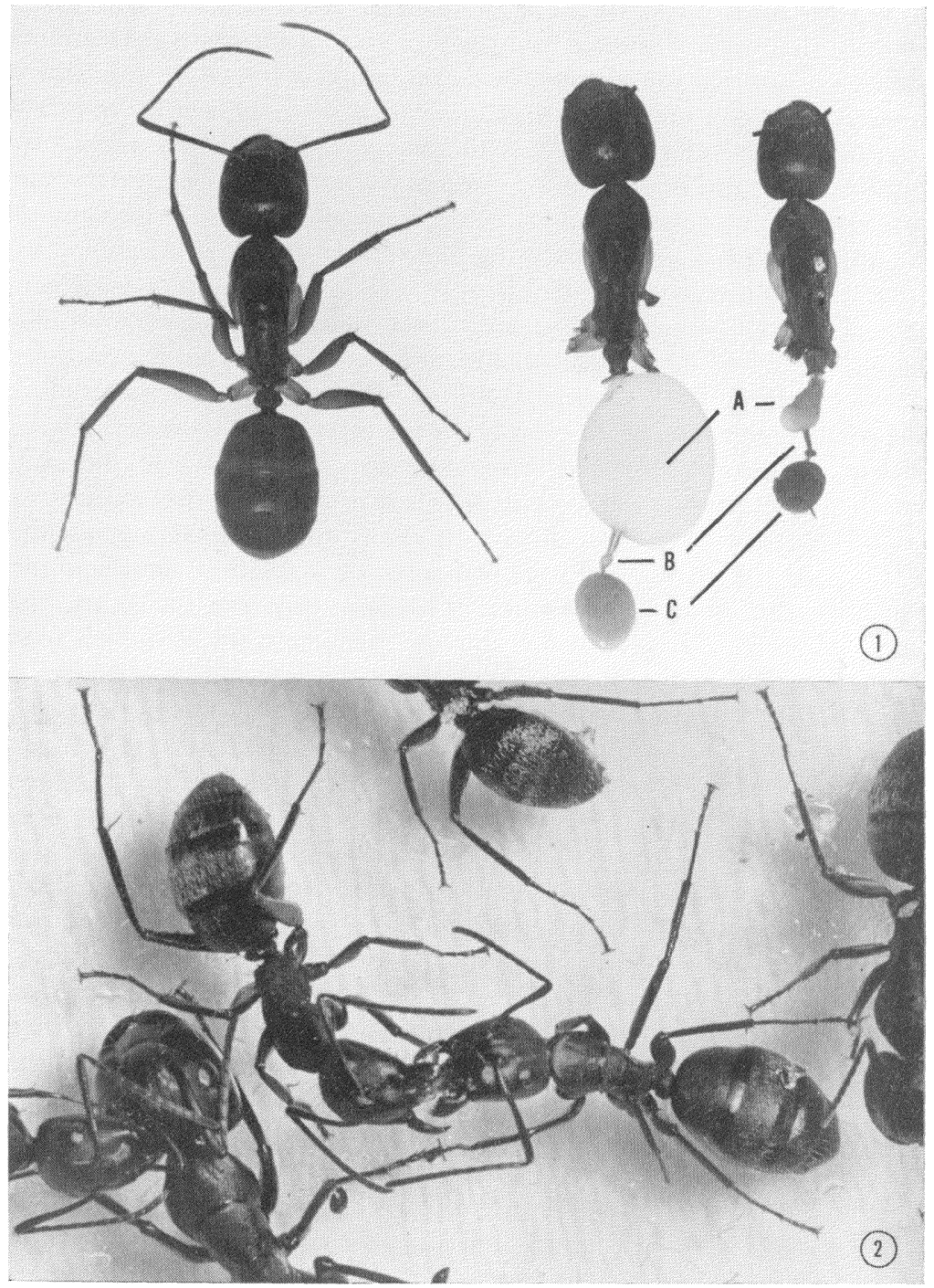

Eisner and Happ - Infrabuccal Pocket 


\section{EXPERIMENTS WITH GROUPS OF ANTS}

Within the formicine ant society, such evidence as we have suggests that regurgitative food transmission proceeds more or less continually - at least during that part of the year when the colony is active. Judging from the increased number of individual regurgitative exchanges that can be witnessed in laboratory colonies that are given renewed access to food following a period of deprivation, it is clear that the arrival of returning foragers with new crop-loads greatly stimulates the overall rate of intranidal exchange. Actual measurements made with species of Formica, fed on food labelled with radioactive tracer, have shown that the crop contents from single foragers may become shared by an entire colony in a matter of hours (Wilson and Eisner, 1957). Although no measurements have been made with Camponotus, it is unlikely that the results with this close relative of Formica would be much different. Evidently, an incoming crop-load, in the course of being passed from ant to ant, and channelled, as it were, through one infrabuccal chamber after another, could be expected to undergo progressive filtration and ultimately be completely cleared of all debris. The following experiments proved that regurgitative feeding does in fact provide a means by which the communal crop supply is filtered and cleared.

Seven ants, fed to repletion on a honey-IO $\mu$ corundum mixture, were each placed in a Petri dish with five unfed nestmates. A color marking differentiated the laden ant from the others. Regurgitative donations took place immediately, at the end of each of which the recipient (previously unfed) worker was removed and killed before it in turn had a chance to donate to others. Dissection of 25 recipients taken in this fashion showed 22 of them to have corundum in their infrabuccal pockets. Thirteen of these had their infrabuccal pockets packed full, and some particles had already passed into their crops.

EXPLANATION OF PLATE 6

Fig. 1. Intact worker of Camponotus americanus Mayr, shown next to two individuals whose appendages have been clipped, and whose gasters have been dissected away to expose the digestive tract. Only crop (A), proventriculus (B), and midgut (C) are shown; the entire hindgut has been removed. Notice the enormously distended crop in the freshly-fed forager (center), contrasted with the crop of a starved individual (right). In Camponotus, as in many other ants, the crop acts as a social stomach, capable of storing amounts of nutrient far in excess of the demands of the individual forager.

Fig. 2. Regurgitative food exchange between two workers of Camponotus pennsylvanicus (DeGeer). This is the process by which the liquid food supply in the crops of incoming foragers is shared with the remainder of the society. 


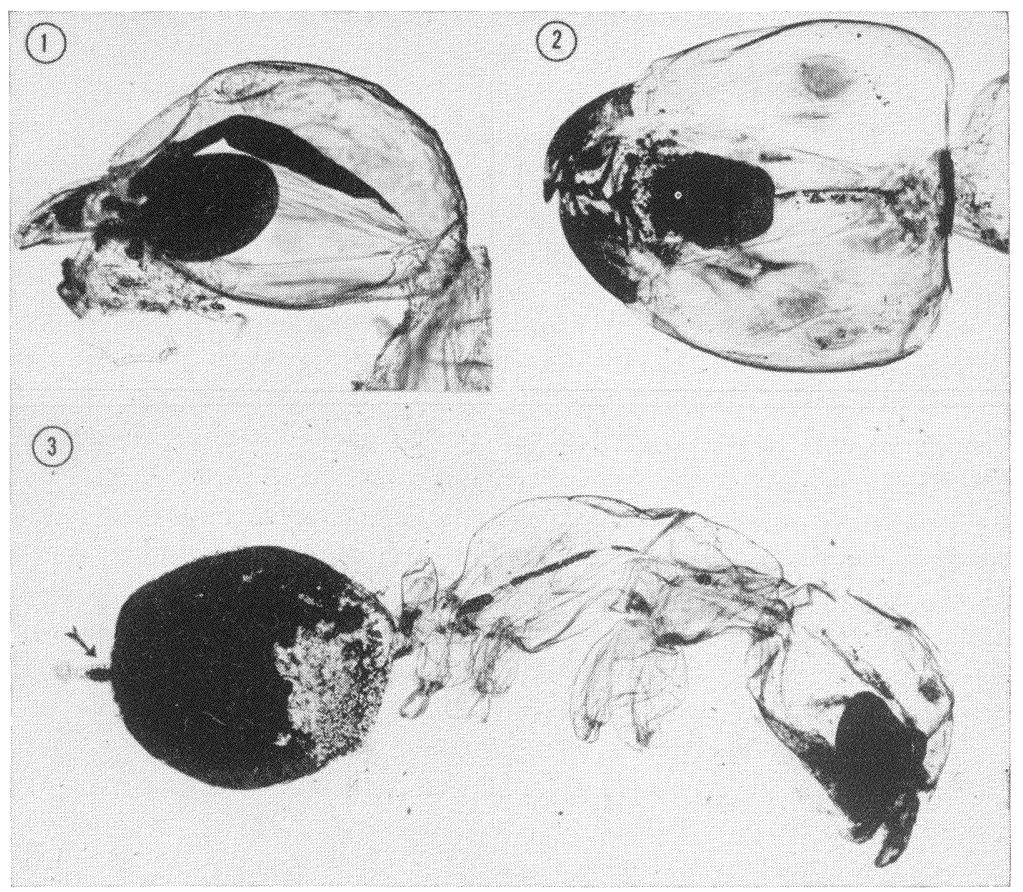

Eisner and Happ - Infrabuccal Pocket

Fig. 1. Profile view of head of worker of Camponotus pennsylvanicus (DeGeer), killed shortly after feeding and cleared in $\mathrm{KOH}$, showing infrabuccal chamber, plus pharynx and portion of oesophagus, densely packed with corundum particles.

Fig. 2. Same as preceding, but of another individual, in dorsal view. The infrabuccal chamber is full, but only few particles are seen in the oesophagus.

Fig. 3. Worker of Camponotus pennsylvanicus (DeGeer), killed shortly after a meal and cleared in $\mathrm{KOH}$, with cuticular shell of gaster dissected away to expose the crop and proventriculus. Notice corundum particles in the infrabuccal chamber, oesophagus, crop, and in the "calyx" (arrow) of the proventriculus. 
Another experiment was designed to replicate more closely the crowded conditions prevailing in actual nests. A total of 35 ants, fed on honey-IO $\mu$ corundum and provided with color markings, were divided into seven groups of five each, and each group was introduced into an observation arena containing 50-75 unfed nestmates. Another 35 ants, similarly fed, served as controls, and were confined each ant by itself. At the end of twelve hours both lots were killed, and a visual estimate made of the corundum contents of their individual crops (one ant of the first lot escaped). The results (text fig. I) were strikingly different in the two batches. Of the isolated ants, nearly every one had the crop filled with corundum to one quarter or more of its capacity. Of those that had been confined socially, about half had completely clear crops, and in most of the remainder the crops were less than onequarter full with particles. Evidently, in the context of the society, debris is rapidly filtered from the communal crop supply. One might add that, whereas in each of the arenas containing the ants in groups there were found at the end of the I2-hour period a dozen or more infrabuccal pellets of corundum, the ants confined singly produced only an occasional single pellet. The pellets recovered in the group-tests stemmed not only from the five introduced food donors, but were actually seen in some cases to have been ejected by residents that had received food by regurgitation. (Ants confined singly over a period of several days sometimes produced more than one pellet. Since during this period they often regurgitated their particle-laden crop contents onto the walls of their glass enclosures, the production of more than one pellet may signify that their crop loads had undergone a series of filtrations as a result of reingestion of the regurgitate. These observations may be of no more than incidental interest, since prolonged lone confinement is obviously not the rule in nature.)

\section{DISCUSSION}

The above experiments show the infrabuccal chamber of Camponotus to be an organ of considerable social importance, in that it serves to maintain the liquid communal crop supply particle-free. It would be interesting to know whether the chamber is a similarly effective filtering apparatus in other ants. In formicines, and in the more advanced dolichoderines, the proventriculi of which are so constructed as to preclude passage of solids, one would certainly expect this to be so. Since the midgut of these ants is never likely to be exposed to the abrasive action of particulate matter, it is noteworthy that a peritrophic 
membrane has been found lacking in those species (including a Camponotus) of these two subfamilies that have been examined. The primitive Myrmeciinae, the proventriculi of which have gaping portals through which small particles could presumably pass, do have a membrane (Waterhouse, I953).

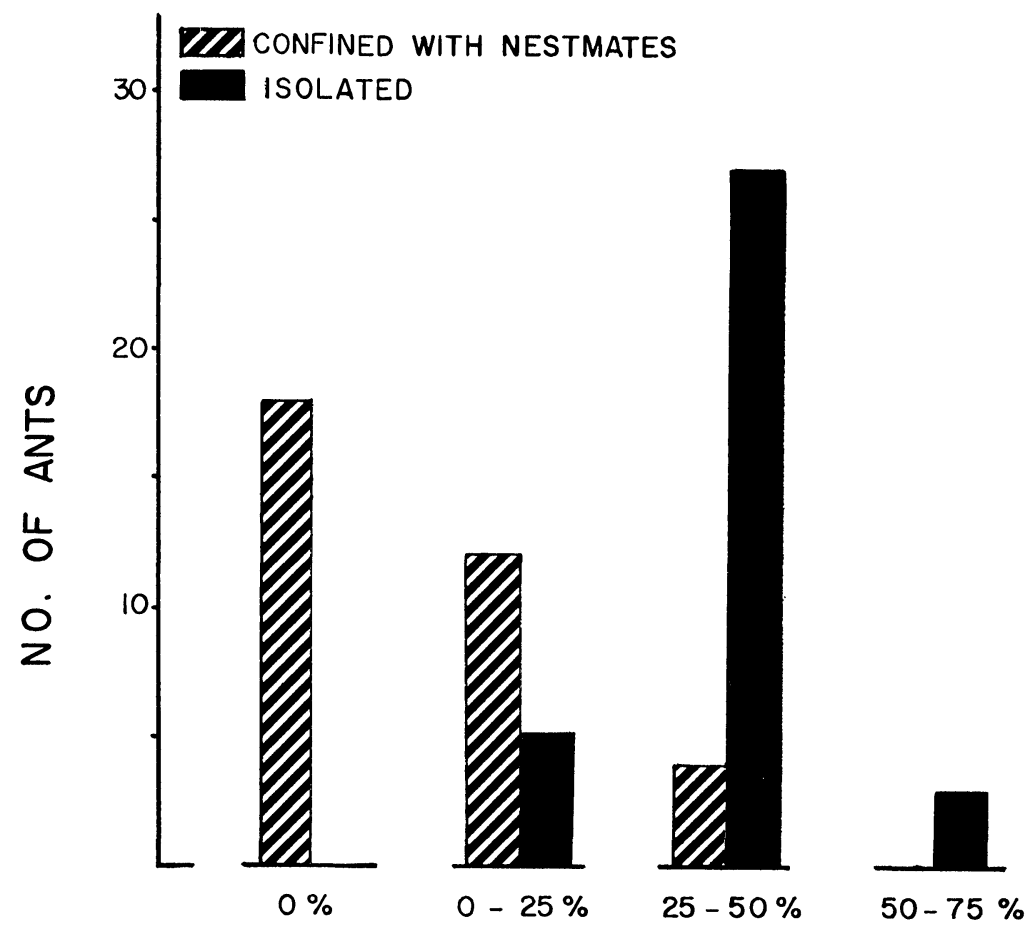

\section{$\%$ CROP-LUMEN FILLED WITH PARTICLES}

Text fig. 1. Frequency distribution of ants classified according to corundum content of their crops. The ants were fed 12 hours earlier on honey laden with $10 \mu$-corundum powder, and were confined immediately after the meal either in isolation (black bars), or together with groups of unfed nestmates (striped bars). See text for details.

One wonders whether, despite the effectiveness of infrabuccal filtration, enough detritus sometimes remains in the crop to interfere perhaps only temporarily - with the normal operation of the proventriculus: particles accumulated over the portal clefts might effectively 
block the passage of fluid during proventricular pumping. In this connection it is of interest that some formicine proventriculi have a special device that apparently serves to wipe the clefts of obstructing solids (Eisner, 1957). In Camponotus, as well as in other formicines with so-called "sepalous" proventriculi, such a device is missing, but since the "calyx" of the proventriculus presumably undergoes rhythmic constriction and dilation during the pumping cycle (the calyx is enveloped by circular muscles), the space within it is likely to be stirred sufficiently to prevent particles from accumulating over the portal clefts on the sepals (Eisner, 1957).

In ants of some of the other subfamilies, the infrabuccal chamber has been shown to serve special functions. Thus, in Atta and certain other fungus growers (subfamily Myrmicinae), the chamber provides the receptacle in which a supply of fungal spores is carried from the parent colony by the departing nest-founding female that must ultimately start a new fungus garden of her own (von Ihering, I 898; Huber, 1905). In yet another subfamily, the Pseudomyrmecinae, the larvae are fed with food pellets compacted in the infrabuccal pockets of the workers, which deposit the pellets in a special postoral receptacle (trophothylax) of the larva (Wheeler and Bailey, I920).

In honeybees, the infrabuccal chamber is apparently inoperative as a filter (Snodgrass, 1956). These insects rely on the intake and digestion of pollen as a protein source for the subsequent manufacture of brood food, and this special requirement can obviously be met only in the absence of thorough preoral filtration. Interestingly, the proventriculus of honeybees is especially adapted to transmit dense pollen suspensions to the midgut without becoming choked (Bailey, 1952).

A representative comparative study of the infrabuccal chamber of Hymenoptera has never been made. In the absence of such a study, it is difficult to speculate on the evolutionary justification for the chamber as it first arose within the order. But since adult Hymenoptera are predominantly fluid feeders, one may reasonably presume that the chamber functioned as a filter from the very outset [its filtering action in at least some wasps has been demonstrated by Duncan (1939) and Janet (1895b)]. To ants like Camponotus, as well as to all other formicines and dolichoderines with an intranidal organization heavily dependent on crop storage and regurgitative food transmission, the infrabuccal filter is thus seen to represent an evolutionary preadaptation of considerable importance. In the absence of an adequate preoral filtration mechanism by which the communal crop supply is maintained particle-free, the proventriculus could not have evolved toward pro- 
gressive restriction of its aperture, and the crop might never have achieved the extremes of storage capacity that it has in formicines and dolichoderines.

\section{References Cited}

BAILEY, L.

1952. The action of the proventriculus of the worker honeybee, Apis mellifera L. J. exp. Biol. 29: 310-327.

Duncan, C. D.

1939. A contribution to the biology of North American vespine wasps. Stanf. Univ. Publ. Biol. Sci. 8 : 1-272.

EISNER, $T$.

1957. A comparative morphological study of the proventriculus of ants (Hymenoptera: Formicidae). Bull. Mus. comp. Zool. Harv. 116: 439-490.

EIsNer, T. and W. L. Brown

1958. The evolution and social significance of the ant proventriculus. Proc. Xth int. Congr. Ent. 2: 503-508.

Huber, J.

1905. Über die Koloniengründung bei Atta sexdens. Biol. Zbl. 25: 606$619,625-635$.

IHERING, H. VON

1898. Die Anlage neuer Colonien und Pilzgärten bei Atta sexdens. Zool. Anz. 21: 238-245.

JANET, C.

1895a. Études sur les fourmis. $8^{e}$ note. Sur l'organe de nettoyage tibiotarsien de Myrmica rubra L., race levinodis Nyl. Ann. Soc. ent. Fr. $63: 691-704$.

1895b. Études sur les fourmis, les guêpes, et les abeilles. $9^{\mathrm{e}}$ note. Sur Vespa crabro L. - Histoire d'un nid depuis son origine. Mém. Soc. zool. Fr. 8 : 1-140.

1905. Anatomie de la tête du Lasius niger. Ducourtieux et Gout, Limoges. Le Masne, G.

1953. Observations sur les relations entre le couvain et les adultes chez les fourmis. Ann. Sci. nat. Zool. sér. 11, 15:1-56.

SNODGRASS, R. E.

1956. Anatomy of the Honey Bee. Cornell University Press, Ithaca, New York.

WALLIS, D. I.

1961. Food-sharing behaviour of the ants Formica sanguinea and Formica fusca. Behaviour 17: 17-47.

Waterhouse, D. F.

1953. The occurrence and significance of the peritrophic membrane, with special reference to adult Lepidoptera and Diptera. Aus. J. Zool. 1: 299-318.

WHEELER, W. M.

1923. Social Life among the Insects. Harcourt, Brace and Co., New York.

WheELER, W. M. and I. W. BaILey

1920. The feeding habits of pseudomyrmine and other ants. Trans. Amer. phil. Soc. n.s. 22 : 299-318.

WILSON, E. O. and T. EISNER

1957. Quantitative studies of liquid food transmission in ants. Insects Sociaux 4: 157-166. 

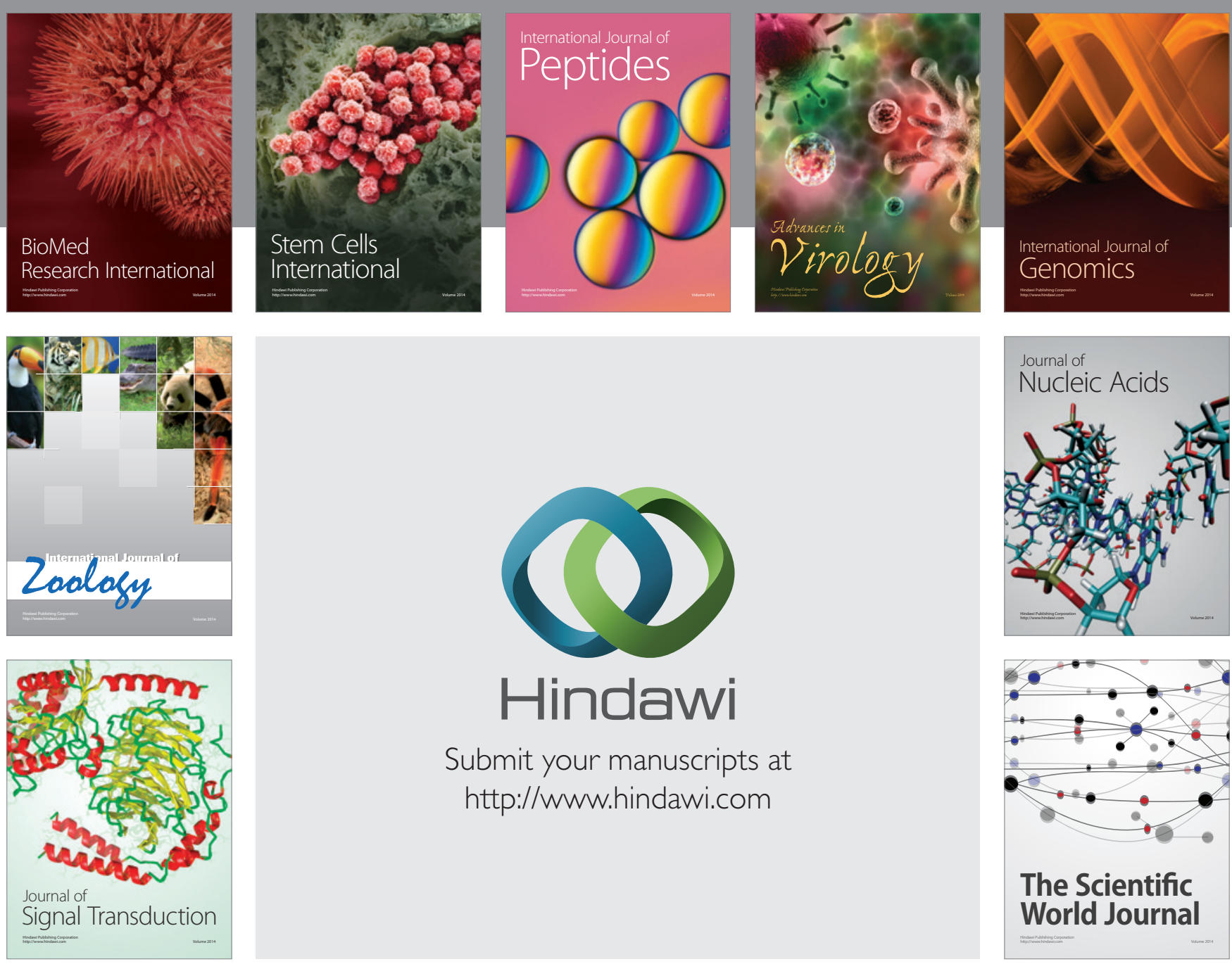

Submit your manuscripts at

http://www.hindawi.com
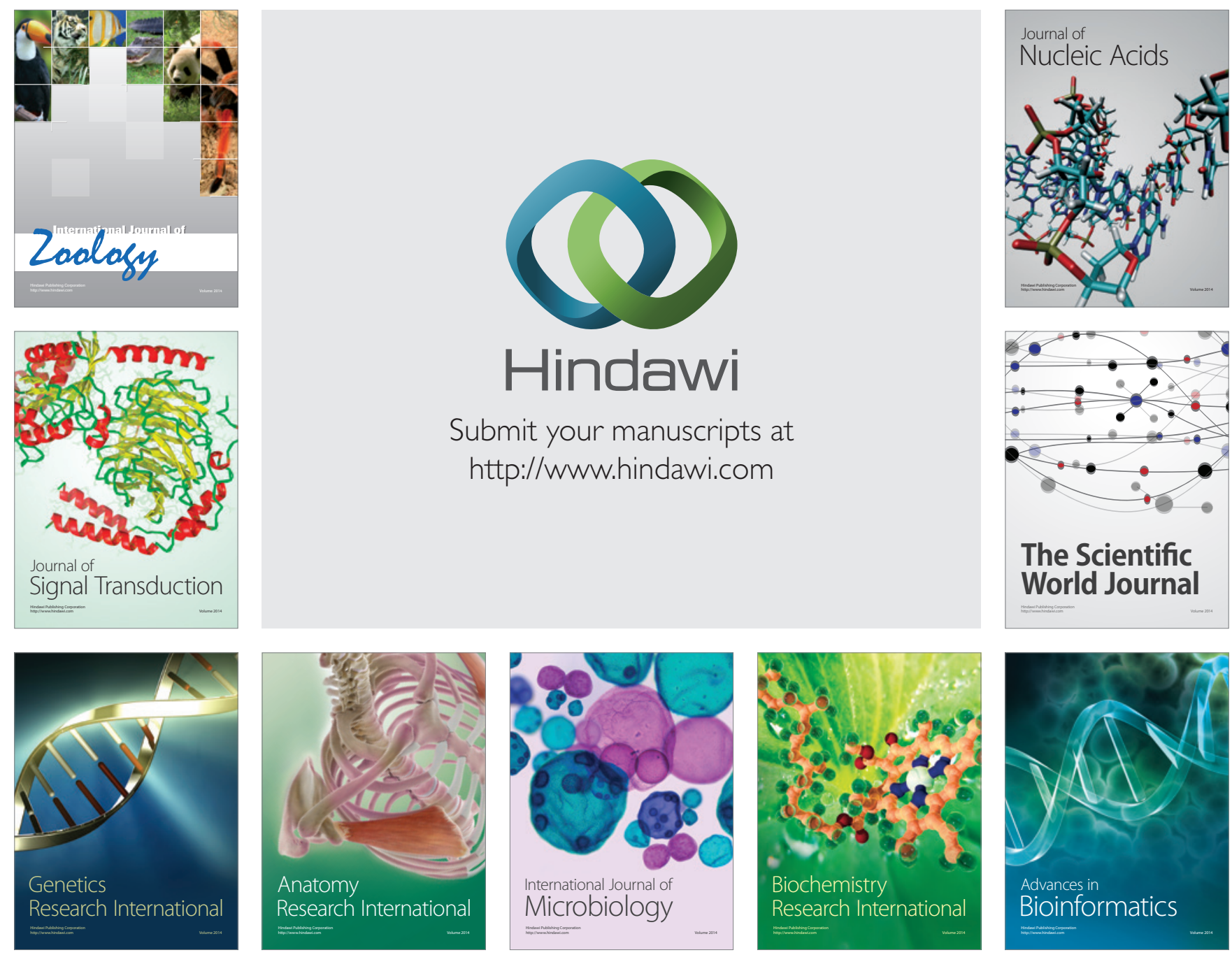

The Scientific World Journal
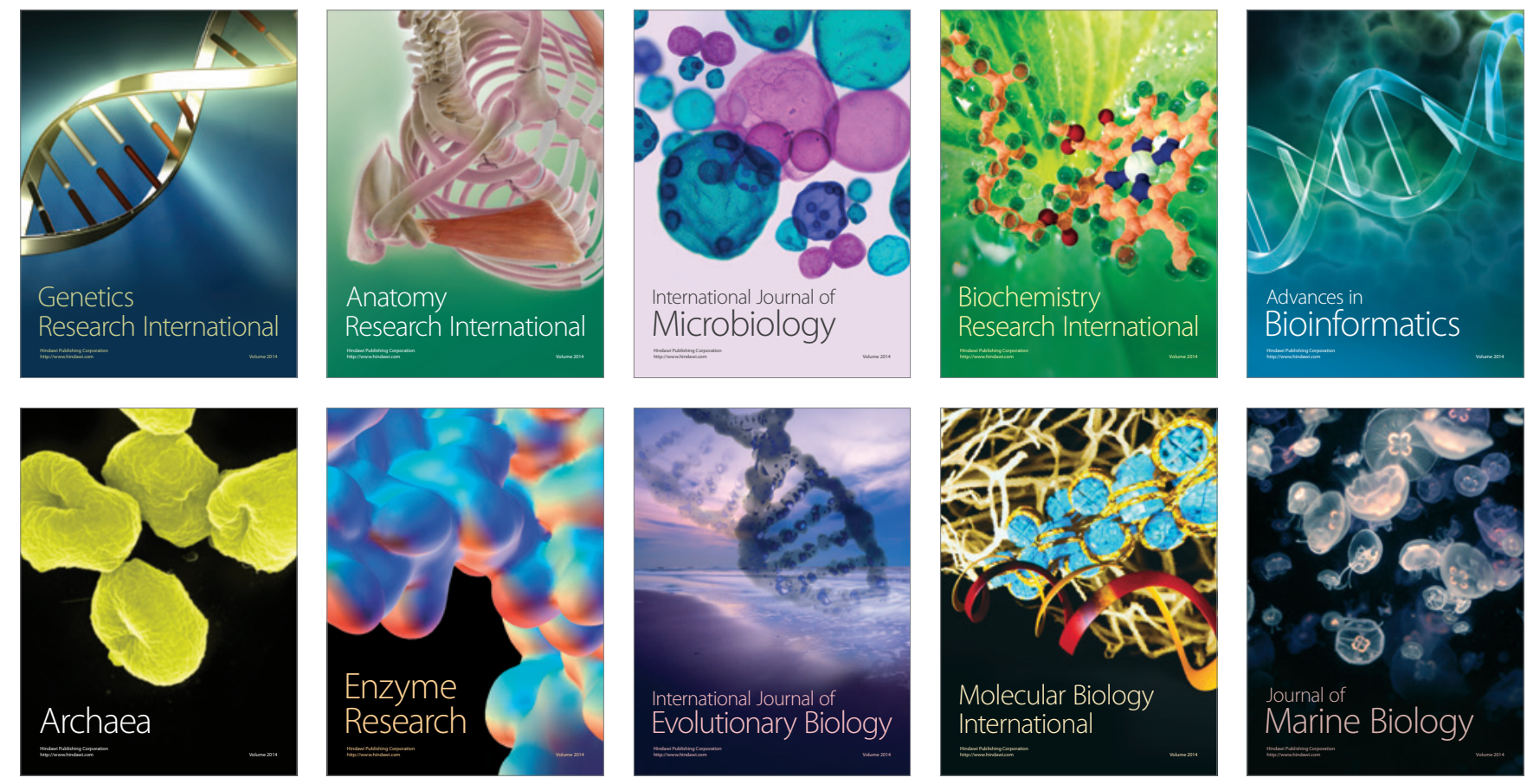